\title{
Ubi medicina, ibi ius
}

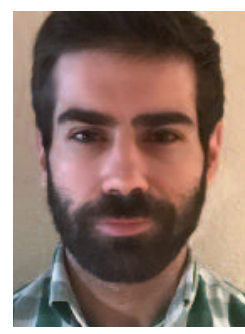

Juan José Andrés Lencina

Médico residente de Dermatología.

Hospital Universitario 12 de Octubre. Madrid. Licenciado en Derecho y en Administración y Dirección de Empresas.
«Donde hay medicina, hay derecho». Permítanme que tome prestado el famosísimo Ubi societas, ibi ius, aforismo latino que nos recuerda que, allí donde hay sociedad, surge el derecho, pero creo que, en el caso de la medicina, viene muy a cuento. La ciencia médica y el derecho no son extraños y caminan de la mano en un mundo en el que los derechos de los individuos - y, por ende, el de los participantes en el acto médico- está cada vez más regulado.

Pero esta relación no es algo moderno. Medicina y derecho llegaron incluso a ser parte de un todo en las primeras civilizaciones, donde la figura del chamán, sabio o sacerdote aunaba ambos mundos, y canalizaba el «poder de los dioses» para la curación o para la resolución de disputas, dependiendo de la situación.

Fuera del mito y la prehistoria, los primeros ejemplos escritos de la relación entre el derecho y la medicina los encontramos ya en la antigua Mesopotamia. El mismísimo código de Hammurabi (el de la ley del Talión; ya saben: «ojo por ojo...»), ya en el 1750 a. C. establece la compensación que se llevará a cabo por el médico que acabe con la vida de un paciente o lo dañe seriamente durante su intervención, si hubiera negligencia (término ya acuñado por aquel entonces) ${ }^{1}$. Las sanciones van desde una compensación económica hasta la pérdida de la mano (malos tiempos para los cirujanos...).
$\mathrm{Al}$ oeste del fértil valle del Tigris y el Éufrates, en civilizaciones como la egipcia, también encontramos esta unión y, en el seno de un primigenio derecho forense, se regula la realización de «autopsias».

La relación progresa y se recoge con más detalle. Ejemplos de ello se pueden observar en el derecho romano. Así, Ulpiano (un importante jurista romano del s. II a. C.) ya describe una Actio legis aquiliae (acción para pedir el resarcimiento del daño) contra el médico que ha operado negligentemente, con todo lujo de detalles y con los pasos que seguir para dicha reclamación. Otro ejemplo lo encontramos en la Lex Cornelia de Sulla, de los años 138-78 a. C. En este documento, ordenaban la supervisión de la prostitución, a la vez que se establecía que el embarazo debía diagnosticarse por cinco comadronas. En el mismo documento, se fijaba un castigo para el aborto (la polémica estaba servida ya desde muchos años atrás).

Este binomio se fortalece también en el Lejano Oriente; así, entre finales del período de los Reinos Combatientes (475-221 a. C.) y el período Han temprano (206 a. C.-220 d. C.), se publicó el «Canon interno del Emperador», que se considera el texto antiguo más importante en la medicina china. Dicho texto se estructura como un diálogo entre el emperador amarillo y uno de sus ministros o médicos, y recoge de forma sistemá- 
tica las características y regulación (legislación) de la medicina oriental de dicha época.

Años más tarde, ya en época del imperio de Carlo Magno, en los años 742-814 d. C., por parte del mundo eclesiástico, tenemos «Las Capitulares». En dichas obras, se remarca la necesidad de que los jueces recaben opiniones autorizadas por médicos en los casos de heridas, traumatismos, infanticidio, suicidio, estupro, bestialidad, en el divorcio y en el diagnóstico de la impotencia (una especie de «protoperitaje»).

Pero la «medicina legal» ${ }^{2}$ o el «derecho médico» son una invención más «contemporánea». Existen ya primeros «acercamientos» en la Edad Media (el primer libro de esta materia fue escrito en China en 1248 por Si-Yuen-Lu) y en la Edad Moderna (Ambroise Paré en el 1575, médico francés considerado padre de la cirugía moderna, escribió otro cuyo contenido se acerca bastante a la que entendemos hoy por medicina legal). Pero es a partir de la segunda mitad siglo XIX cuando en Europa surgen normas tan básicas como la autorización para el ejercicio de la medicina o conceptos como el de «seguridad social», con el aparataje legal que ello supone.

La seguridad social ${ }^{3}$, como exponente de esta «nueva relación», nace en Alemania, en la época del Canciller Otto von Bismarck, con la Ley del Seguro de Enfermedad, en 1883. La expresión «seguridad social» se populariza a partir de su uso por primera vez en una ley en Estados Unidos, concretamente, en la Social Security Act de 1935. Posteriormente, el concepto es ampliado por sir William Beveridge en el llamado «Informe Beveridge» (Social Insurance and Allied Services Report) de 1942, con las prestaciones de salud y la constitución del National Health Service británico en 1948. Japón, antes de la Segunda Guerra Mundial, es uno de los principales impulsores mundiales de la seguridad social, creando el Ministerio de Sanidad, Trabajo y Bienestar y su propio sistema de pensiones e incapacidad.

En España, dicho camino discurre de forma paralela y, ya en 1900, se crea el primer seguro social, la Ley de Accidentes de Trabajo. En 1905, se crea el Instituto de Reformas Sociales y, en 1908, también con gobierno conservador, el Instituto Nacional de Previsión. En 1919, se crea el Retiro Obrero y, en 1929, el Seguro de Maternidad. La primera vez que se legisla sobre protección social en norma básica constitucional es en 1931, cuando la Constitución de la II de la República, en su artículo 46, recoge textualmente: «El trabajo, en sus diversas formas, es una obligación social, y gozará de la protección de las leyes. La República asegurará a todo trabajador las condiciones necesarias de una existencia digna. Su legislación social regulará los casos de seguro de enfermedad, accidentes, paro forzoso, vejez, invalidez y muerte $[\ldots] »$.

Y así, poco a poco, se fue forjando una relación que perdura y se intrinca y se complica hasta límites insospechados y que sigue y sigue regulando a este complejo dúo que son la medicina y el derecho (las recientes leyes de autonomía del paciente, de protección de datos o la novísima Orden de 19 de enero que regula las «pautas básicas» destinadas a asegurar y proteger el derecho a la intimidad del paciente por los alumnos y residentes en Ciencias de la Salud).

Muchas situaciones y muchos frentes aún por regular en una relación cada vez más compleja, tanto que hace pensar si en un futuro serán necesarios nuevos «chamanes» $\mathrm{o}$ «sabios» que vuelvan a dar sentido a todo este galimatías de leyes, decretos y derivados y nos digan «la voluntad de los dioses legisladores» sobre cómo ejercer el noble arte del primum non nocere.

\footnotetext{
BIBLIOGRAFÍA

1. Wecht $\mathrm{CH}$. The history of legal medicine. J Am Acad Psychiatry Law. 2005;33(2):245-51.

2. López Ábrego LA (ed.). Enciclopedia, Criminalística actual, ley, ciencia y arte. México: Euroméxico; 2013.

3. Ministerio de Empleo y Seguridad Social. Historia de la Seguridad Social. [Internet]. Disponible en: http://www.segsocial.es/Internet_1/LaSeguridadSocial/HistoriadelaSegurid47711 /index.htm
} 